\title{
"The preservation of order": the use of common approach among staff towards clients in long-term psychiatric care
}

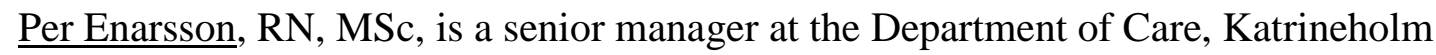
Municipality, and a doctoral student at the Department of Advanced Nursing, Umeå University, Umeå, Sweden; email: per.enarsson @ katrineholm.se

Per-Olof Sandman, RN, DMSci, is a professor at the Department of Advanced Nursing, Umeå University, Umeå, Sweden; email: po.sandman@nurs.umu.se

Ove Hellzén, $\mathrm{RN}, \mathrm{PhD}$, is a associated professor at the Department of Health Sciences, MidSweden University, Sundsvall, Sweden; email: ove.hellzen@miun.se

Correspondence to:

Per Enarsson

Department of Care

Katrineholm Municipality

Upplandsgatan 2

S-64180 Katrineholm

Sweden

Phone: +46150 57599

Email: per.enarsson@katrineholm.se

Key words: common approach, grounded theory, negotiation, nursing, psychiatry 


\section{ABSTRACT}

This grounded theory study was performed to gain a deeper understanding of the kinds of social processes that lead to a need in psychiatric nursing staff for reaching a common approach on how to act towards individual clients in long-term psychiatric care. We present a theory about the development of such common approaches among staff. Our main findings were that in psychiatric group dwellings, when the internal order is perceived as having been disturbed, the need arises for the staff to "preserve or restore the internal order" by formulating and reaching a common approach. To do this, the staff negotiated with each other in order to achieve an agreement on how to act and behave towards the individual client. In this paper we isolate and describe different types of order-disturbing incidents and the common approaches taken by the staff in dealing with them. However, our data also show that when a common approach was put into practice the staff often had difficulties in maintaining it over time.

\section{INTRODUCTION}

In Sweden, clients suffering from long-term mental illness are often cared for in small, community-based group dwellings, each housing between four and twelve clients. Each client is furnished with individual quarters, for which rent is paid, and given access to adjacent communal areas and areas in which staff are located (National Board of Health and Welfare 1999). The staff provide psychiatric care and assist the clients in managing their day-to-day activities.

One common clinical observation in psychiatric care is that care is often based on rules imposed by the staff. For example, within a group dwelling, the staff may have established certain areas which are staff-only, and which clients may not enter. When a client violates this 
custom, and does not respect the staff's requests to leave such an area, the internal order of the community may be perceived as being under threat. In such cases, there may be a need for a common approach to be directed toward the individual patient, or, in other words, a decision needs to be made as to how to act towards the client in this specific situation.

This example raises a number of questions. How can we understand the social processes which take place when staff propose a common approach for dealing with a client in a certain situation that is perceived by the staff as difficult to cope with within existing routines? What kinds of situations trigger the need for a common approach?

\section{Earlier studies of social processes in psychiatric contexts}

The term "social processes" is formed from the word "social", defined as "relations between people in a community", and the word "processes", defined as "connected series of actions and changes such as are deliberately, involuntary or unconscious" (Hornby 1974). One such social process is "social interaction", which Goffman (1971) describes as something taking place between humans in a complicated ritual of gaining control through communication. Studies of social processes are thus of great interest in the attempt to understand what is happening in communication between staff and patients in psychiatric care.

Several studies focus on social processes in nursing, examining the interactions and communication between staff and patients in a psychiatric context. Bunch (1983) used grounded theory to study communication patterns between psychiatric nurses and patients with schizophrenia. Crabtree (2003) performed an ethnographic study concerning staff attitudes towards psychiatric work and patients. In an interview study using grounded theory, Lutzén \& Schreiber (1998) investigated psychiatric nurses' ethical decision-making processes 
in a non-therapeutic environment. Another study focusing on situations in which patients did not cooperate with a nursing decision about what should be done for them employed a method inspired by grounded theory (Lutzén 1998). However, no research has yet attempted to describe and understand the social processes per se, in a long-term psychiatric care context, that lead to a need among staff to formulate a common approach and to act towards an individual patient in accordance with this approach.

\section{Exposing the care culture}

To better understand why staff take a certain attitude towards patients in psychiatric care, it is necessary to describe the care culture, which can be said to create the frame of action of the staff. The care culture consists of a system of ideas shared by staff — rules and ways of thinking — which affects the attitudes of staff in the performance of daily care (cf. Sarvimäki \& Sandelin Benkö 1998). The traditional psychiatric care culture makes the encounter between staff and patient hierarchical and task-oriented rather than relation-oriented (cf. Foucault 1983; 1987), resulting in an imbalance in power (cf. Foucault 1983). Today, even though psychiatric care in Sweden has become increasingly de-institutionalized (National Board of Health and Welfare 1997b; Stenbak et al. 2000) and is provided in outpatient facilities in order to treat patients without isolating them from society (cf. Åström et al. 1993; Shepherd et al. 1995), there are still traces of what Goffman (1991) refers to as the "total institution". This is characterized by a hierarchical structure, in which patients are subordinated to staff and often feel humiliated, and which is arranged around fixed rules, including a reward and punishment system in which staff can exercise their power. Goffman writes about the "moral career" of the psychiatric patient, a label which signifies a formal recognition of the patient's illness and is a first step towards giving the carer some social control over the patient. This is achieved through institutional structures for reward and 
punishment (Sjöström 1992). Studies show that the characteristics of the total institution described 50 years ago still remain today, both in inpatient and in residential treatment settings (Shepherd et al. 1995; Stuart \& Sundeen 1995; Zimmerman 1996). Crabtree (2003) has revealed how the "asylum model" can influence staff into attaching stigmas and prejudices to mental illness in their daily work.

\section{Attitudes held by staff towards patients in psychiatric care}

Nursing staff in psychiatric care hold several different attitudes towards their patients. Hellzén et al. (1995) describe how patients suffering from schizophrenia and the staff who cared for them perceived each other. Two different staff attitudes emerged, the relationship-oriented and the task-oriented approach. Relationship-oriented nurses had a more "long-sighted" view of their work, while more task-oriented nurses focused on practical activities. Bunch (1983), studying communication patterns between psychiatric nurses and patients with schizophrenia, showed that nurses would use one of two strategies when interacting with the patient, either focusing on the internal rules of the institution (and consequently often medicating or isolating the patient) or negotiating with the patient concerning agreements and good behavior.

For their part, patients who were interviewed stressed the need for forming human relationships, and the wish for the carer to be genuine and humane (cf. Skovdahl et.al. 2003; Pejlert et al. 1995; 1998).

\section{Rationale for the study}

This study was performed to further increase our understanding of the kinds of situations which psychiatric staff perceive as being difficult to cope with within existing routines. We 
also wanted to deepen our insight into which kinds of processes lead to a need among the staff to formulate and act in line with a common approach directed toward an individual client.

The aim of this study was therefore to understand and describe the social processes, in a longterm psychiatric care context, that lead to a need among staff to formulate a common approach and act towards individual clients in accordance with this approach.

\section{MATERIALS AND METHODS}

\section{Setting and participants}

Two group dwellings for clients with mental illness in two different communities in the south of Sweden were selected. In each group dwelling, contact was first made with the person in charge and then staff and patients were approached about participating in the study. The staff informed the clients individually, and obtained written consent from them. All staff and clients agreed to participate in the observation part of the study. Separate written consent was obtained from each person who was asked for an interview. Four clients and two members of staff declined to participate in the interviews. In total, 25 staff members (18 women) and 16 patients (nine women) were included in the study. One staff was a registered nurse, twenty staff was enrolled nurses with psychiatric training and four staff had basic training for homecare duties for the disabled in the community. Because the units are small and to prevent them being recognized they are presented as a whole, not as single units.

The first group dwelling was located in an apartment block containing four two-room apartments and one staff apartment. Four clients lived in the group dwelling and another ten clients lived in the neighborhood, receiving support from the same staff. The other group dwelling was located in a converted kindergarten. Eleven clients lived in this group dwelling 
and another nine clients in the neighborhood received support from the staff. This group dwelling contained communal areas and a staff apartment.

Most of the staff were nurse's aides or enrolled nurses with or without psychiatric training. One (part-time) registered nurse was also included. One group dwelling also included staff members who had no education in caring but had a university degree in social science. In both places, all staff had previous experience of work in the social services, home care or psychiatric care. The ages of the staff ranged from 20 to 60 years. In most cases, the clients had suffered from their psychiatric illness for several years and many of them had spent time in mental hospitals. The majority of clients were between 20 and 50 years old. All clients had reduced ability to cope with daily routines, such as shopping, cooking, and budgeting. Most of the clients were unemployed, and spent most of their time inside the group dwellings.

Four people from the Swedish National Association for Social and Mental Health (RSMH), all of whom had experience of mental illness and being cared for within the mental health system, were also selected for interview. They were informed by a voluntary worker about the study, and asked whether they wanted to participate. Written consent was obtained from each participant.

In the presentation of the results, all clients are referred to as "he" and all staff as "she" in order to conceal identities and simplify the reading of the results. In reality, both genders were represented in both groups.

\section{Data collection}


Grounded theory was used as the basis for data collection and analysis (Glaser 1978; Glaser \& Strauss 1967). Direct non-participant observations (cf. Patton 1990), semi-structured interviews (Polit \& Hungler 1999), and focus group interviews (Kvale 1996) were conducted.

To ease the socialization process, four visits were paid to each group dwelling at one-week intervals. Observations were conducted over a period of ten months, with each observation session lasting for approximately four hours (in total, there were 46.5 hours of observation performed at eleven separate occasions). Different situations were observed, for example, formal and informal meetings between staff and clients, and meetings with only one party present. A number of places were chosen in which to observe staff-client interaction. The principal place was situated near facilities where the staff took a break, or in the clients' lounge, which was also a good vantage point from which to keep track of what was happening in the hallway. Field notes and tape-recorded memos were constantly taken during the observations and were later transcribed verbatim and expanded (cf. Rodgers \& Cowles 1993).

Once staff and clients became more used to the observer, individual semi-structured interviews were conducted. The interviews with staff took place in a private spot, while all the clients chose to be interviewed in their own apartments. An interview guide based on the initial observations was used, and was revised as new data emerged. Staff and clients were invited to talk freely about their experiences of a common approach. The questions used were along the lines of, for example, "Tell me about a situation in which you and your colleagues experienced difficulties in dealing with a client and felt the need to find a common approach to handle the situation" and "Can you give me an example of when your view differed from that of staff concerning the support you get from them?". The interviewees were encouraged to speak as freely as possible and follow-up questions were asked to stimulate their narrations. 
A tape recorder was used and all interviews were transcribed verbatim. In total three interviews with staff and four interviews with patient were performed, containing six and a half hours respectively four hours recording.

Once theoretical outlines started to emerge in the analysis of observations and interviews, we wanted to further stimulate staff and clients' narratives in order to deepen our understanding of a common staff approach. Therefore, focus group interviews were conducted on two occasions, the first with four staff members early on in the data collection. The session was tape-recorded, containing one and a half hour recording, and later transcribed verbatim. Because the material from the client interviews was limited, with several clients having evident difficulties in expressing their views on the support given to them by staff, members of a focus group were also interviewed at the end of the data collection period. The focus group comprised four people from the Swedish National Association for Social and Mental Health (RSMH). The members of this group were asked to reflect upon the preliminary findings of the study. Because of the noisy environment in which the interview took place it was not possible to make tape recordings, so only field notes were taken. This session lasted one and a half hour.

\section{Analysis}

Data were collected and simultaneously subjected to initial analysis. As well as field notes and transcripts from the interviews, various process notes and memoranda were used. Rogers and Cowles (1993) argue that the qualitative researcher should develop an audit trail. Such an audit trail should contain the researcher's feelings, thoughts, ideas, hypotheses, choices, and methodological considerations. In the case of this study, the principal researcher (PE) wrote "memos", or notes, on ideas, conjectures, and hypotheses throughout the entire process of 
data collection and analysis. A "log", including substantive, methodological, and analytical notes (cf. Rodgers \& Cowles 1993). One example from an analytical part of a memo is as follows: "Interview 5, client interview, analytical notes: Hard to find clear situations (in this interview) connected to common approach among staff. Can it be that the client doesn't apprehend the common approach but sees it as a natural part of the ongoing treatment?" Writing memos proved to be most important in the analysis process, aiding reflection on the data generated and on the impact of the investigator's bias. In the first step of the analysis, the substantive coding, the "Open Code" computer program (Starrin et al. 1997) was used. All authors have read all the gathered material and discussed the analysis constantly in order to ensure validity

Once categories started to take shape, the collection and theoretical coding of new data became more selective. A core category was detected as central to the research question, and was validated by the other categories. The categories were determined in relation to the core category with the aim of formulating a theory. After about 35 hours of observations and nine interviews, no additional categories appeared in the analysis of the material (i.e., theoretical saturation had been reached). However, as this break point was not detected until later on in the process, further data were collected. Data collected beyond the break point merely confirmed the results, but were also included in the analysis.

All categories were grounded in data of a mostly repressive and "negative" nature. A specific analysis was performed to search for data describing a common approach among staff relating to a positive experience of the client. However, no such data could be found, either in the interviews or in the observations. Consequently, data describing negative episodes predominate, as will be shown in the Results section. 


\section{Ethical considerations}

The Ethics Committee at Örebro University granted permission for the study on May 21, 2002 (registration number 989/01). Special attention was given to explaining the purpose of the study for the client and to the vulnerable situation the client was in when asked by staff to join the study. All participants were given time to reflect on whether they wanted to join the study.

\section{RESULTS}

\section{Internal order}

It has been shown by Foucault (1983) that a psychiatric institution has an internal order, i.e., a structure, fixed principles, and distinct roles that separate staff from clients. This kind of internal order was also seen in the settings studied here. Another aspect, seen in observations and confirmed in interviews with staff, was the intention of staff that the institution should imitate the surrounding society in striving for normalization. The internal order of the institution became visible when, for example, we observed a client who was not allowed to have visitors in his apartment, wear outdoor garments inside, or contact staff in his spare time. Many of the norms seemed invisible in daily life and only emerged in various routines (cf. Goffman 1991). Underlying norms held by staff had to be "exposed" in observations and interviews and reflected upon in order to make them visible to the investigators.

\section{Core category: The preservation or restoration of order}

An order-disturbing incident which could not be dealt with within existing routines, and for which no similar previous experiences were available to base solutions on, led the staff to restore order by assuming certain attitudes and/or acting in certain ways towards a client. Characteristic of this process was that staff negotiated a suitable way of handling the situation 
among themselves, with the client involved having little or no knowledge about, or influence over, the process. The staff aiming to preserve or restore order formulated a common approach. If it was judged to be successful, i.e., if order was restored, a new routine was formulated for use in similar situations in the future. If it was not considered successful, the process might start again, with a new common approach being discussed and then tried out in practice.

\section{Category: Incidents that disturb the internal order}

Incidents sometimes occurred that disturbed or threatened to disturb the defined order. A client may have done something which the staff perceived as harmful to either him or themselves. Several such order-disturbing incidents were observed. The incident could have been an isolated incident which triggered a staff response because of its magnitude - for example, a client could have hurt himself. Other examples would be a series of minor incidents taken together, or incidents occurring with increased frequency. Neither the type nor the magnitude of incident that would trigger the need for a common approach seemed to be fixed; rather, the call for a common approach was dependent on factors such as feelings of security among the staff and how well the staff knew the client. Crossing the boundary that defined the appropriate level of closeness between staff and client could also constitute an order-disturbing incident. For example, a client might contact a member of staff on her day off or go up to her in a public place. This type of behavior would challenge the staff's norm of the social order. Several members of staff narrated about this type of incident:

Some clients can be a pain in the ass with their inquisitiveness. We only talk about trivial things when such a client is present ...//... It is important to remain professional. When you live in a small place it can be bothersome to run into a 
client in your private life. The client should respect the staff's right to a day off work, and to privacy.

Another kind of order-disturbing incident was an action by a client which was judged by staff to be socially unacceptable. An example of this may be a client who has an unhealthy style of living, or dresses in a provocative manner, or has an untidy hairstyle. Such a client violates the norms of good behavior and a healthy lifestyle, and challenges the ideas that the staff have about appropriate behavior.

Inside the institution, the staff defined the areas clients were allowed to enter. Most clients seemed to accept this custom, but occasionally a single client would cross the border and enter a prohibited area. Clients were observed standing at the border of the prohibited area, which could be a doorway or an invisible line on the floor, waiting for permission from the staff to enter. If a client did not respect this border, staff might feel that the internal order was being threatened. This would lead to a common approach among staff on how to handle the client. One client narrated about his experiences:

In the group dwelling, staff sit and talk .../... If a client comes in they all go quiet and ask, what do you want? I think it is a cold staff group.

Incidents that disturbed the internal order also occurred when a client acted in a way that was perceived by the staff to be dangerous for him. Examples of this are when a client did not take his medication, or isolated himself, or hurt (or threatened to hurt) himself. One client drank too much water and had to be taken to hospital for emergency medical treatment. The staff decided on a common approach to prevent such a situation from occurring again; the water 
was turned off except for showers and the client was only allowed to drink a certain amount per day.

Another kind of order-disturbing incident was when a client was thought to be doing something which was felt to be dangerous for the staff, such as being violent, uttering threats to hurt the staff, or, as happened in one case, detaining a member of staff against her will in the client's apartment. In that particular case, the staff decided on the common approach of not visiting that client any more.

Incidents that disturbed the order also included incidents in which a client behaved in a way that caused conflict among the staff. For example, one client gave inaccurate accounts to each of the day and night shifts of what the other had told him. The staff became accusatory towards each other, which culminated in their adopting a common approach as to how to act towards the client in order to avoid further conflicts. Other examples of such incidents occurred when staff were criticized by the client, especially when a single staff member was criticized. Clients could contact supervisory authorities to complain. Several staff members expressed the belief that they were the weaker party in any encounter with the clients, and that patients had all the rights on their side while the staff had only obligations. This short dialog between two members of staff attending a focus group illustrates this belief:

Staff 1: No, the decisions we take are about $\mathrm{N}$ and intended for ...

Staff 2: He (the client) will surely contact the manager in the end ...

Staff 1: Then A and B (managers) would phone in five seconds and ask what the hell are we doing? 


\section{Category: Negotiation among staff about how to act}

When various members of staff made different interpretations of a situation experienced, it became necessary for them to negotiate over how to act towards and deal with the client in the actual situation. For example, one client chose to eat in his own room, avoiding social contact with other clients and staff. This was experienced as a threat, which had to be resolved, to the internal (social) order at the group dwelling. In addressing the questions of whether the client should be forced to eat his meals communally in order to break his isolation, and how staff should achieve this goal, the members of staff had to negotiate to find a generally acceptable solution. In such a situation, if a compromise could not be reached, the stronger party, often the majority or those with influence among the staff, determined how they would act and deal with the client. Negotiations often took place during formal and informal staff meetings. The following notes were made at such an informal meeting with the "weaker party", gathered to discuss how to motivate a client to eat his meals communally:

Members of staff present narrate that there is a conflict. The staff are divided in two fractions. The others do not listen to us, one says. We want the client to have some occupational therapy and to be given to understand that food is prepared and eaten together with others.

If a single staff member wished to impose her view on how they should deal with a client, she could gain support through allying herself with other colleagues. Our data show that the client was not involved in, and often had no knowledge of, the decisions and negotiations carried out by the staff. One client narrated: 
But the usual way is, I suppose, closed meetings where the client is not allowed to participate and then, when staff are agreed, they inform the client.

One member of staff described a similar experience, but from a different angle, when the client was present. She said that it was important as staff to "stand united" in front of the client in order to emphasize stability and security, not letting the client witness any disagreements among staff:

If a single member of staff says that is the way it is, you must always agree with her when the client is present. You can make your opinions and thoughts known afterwards.

When negotiating a common approach, the staff tried to keep a balance between maintaining conformity in the way a client was dealt with and their individual need to interpret a situation on an individual basis. There was the realization that a common approach could not cover all the situations a member of staff might be faced with. However, there was also the requirement that every staff member must be prepared to justify, in front of her colleagues, any failure to keep to the common approach. This happened once when a staff member did not treat the client in the way the majority had agreed on. She had bought the client "unnecessary things" that he had said he wanted and she was subsequently criticized by her colleagues for not keeping to the common approach.

\section{Category: Choice of a common staff approach towards a client}

The staff seemed to be constantly maneuvering in their efforts to prevent clients and colleagues from disturbing the equilibrium. Members of staff became watchdogs, always on 
the lookout for incidents that might disturb the order. The common approach became a means of trying to restore the internal order in the group dwelling, and was often presented as being aimed at improving life for the client, i.e., as being introduced for reasons of security and stability. One member of staff said:

The framework. All humans do need a basic framework. I mean, it is there when you grow up ... . We cannot turn the world upside down, for example; that would not feel good. We must have structure. Even if you think you are doing nothing, and you have no structure, and so on, you still need to have it. And I think everyone has it .... And in a way, we (the staff) were placed here to give these people (the clients) some kind of security.

If an order-disturbing incident could be dealt with within existing routines or with methods based on earlier experiences, it was expected that order could be restored without the need for a common staff approach. For example, a client who was admitted to a psychiatric clinic, and felt uneasy or restless, wanted a cup of coffee in the night. However, since clients were not allowed in the kitchen area, the patient did not get his coffee. The staff motivated their standpoint by saying that they wanted to help him to establish a proper circadian rhythm. Every client who asked for coffee during the night got the same answer.

However, an incident that could not be dealt with within existing routines would trigger the need for a common approach among staff. For example, when a client threatened the internal order by frequently seeking out the staff for advice and never leaving them alone, the staff adopted a common approach aimed at acting towards, and dealing with, the client in a certain way. They agreed on a tight schedule for the client, with activities such as waking up, breakfasting, having a cigarette, and going to the toilet scheduled in quick succession in order 
to control most of the client's time and activities and thereby reduce his attention-seeking behavior. Another example of a common approach was the policy adopted after a client was perceived to threaten the social order at the group dwelling by getting too close to the staff. The staff tried to impose a common approach that clearly separated them from the client and made sure the client did not try to cross the staff-client boundaries. When the client went to sit with staff around a table, the approach was exemplified by the client being the only person at the table who was not offered coffee. The staff had felt that the client was demanding in his manner, and had reached an agreement on adopting a common approach not to invite him or encourage his presence.

In striving to maintain or restore order, staff could also use a more repressive common approach. In such a case, the power held by the staff in their relationship with the client became more obvious. For example, if the staff thought that a client dressed oddly, or had a strange hairstyle, they could see this as a threat to the norms in society as well as the norms in the group dwelling, which could jeopardize acceptance of the client. One such agreement resulted in the staff giving a client a haircut against his will because they thought he looked untidy. If there was any disagreement between staff and a client about how to solve a problem, the staff often seemed to have the right to interpret the situation and impose their interpretation on the client. In one case, a client was not allowed to wear outdoor garments while inside the group dwelling because it was against the norm set by the staff. The staff took the common approach that if the client did not take his jacket off then they would lock it away. Staff saw their position as superior to that of the client; they acted in a "fostering" manner. The client seemed to be treated like a child. Several staff in fact said that you should treat the client like a child - kindly but firmly. 
A common approach was also adopted to protect the clients, and prevent them from getting into situations that the staff perceived as dangerous. A common approach could also focus on events that had already taken place, to ensure that they would not recur. One example of this would be the previously-mentioned decision to turn the water off in a client's apartment in order to prevent him from drinking too much water again.

Protecting the staff from a client was another inducement for determining a common approach. In such cases (e.g., clients making verbal and physical threats, including threats about reporting staff for mistreatment), the staff tried to reveal as little as possible of themselves as individuals. One way of doing this was to minimize talk about their private lives when a certain patient was present, as the following quotation from a staff interview shows:

Interviewer: How much do you as staff tell the client about yourselves?

Staff: Not much. We decided previously not to reveal our surnames but the client found out anyway.

\section{Category: Putting a common approach into practice}

Once a common approach on how to treat a certain client had been negotiated and decided by the staff, it was put into practice when staff interacted with the client. If a common approach was maintained over time, it could lead to the establishment of a new routine, providing the staff with a strategy for dealing with similar situations in the future. This sequence of events meant that the staff felt they had gained new knowledge. A member of staff narrated this on the issue of clients who would search the staff office for written messages: 
Now everyone performs in a similar way (when reporting to the next shift). In the past, the others did so and so [explains]. It is fairer when everyone works in the same direction. The advantage is that we protect each other. We don't need to worry about some of us working in the wrong direction.

A common approach on how to deal with a client could also be maintained over a certain period and then be discontinued, for instance because the condition or behavior of the client had only called for specific actions during a limited time. One client suffered temporarily from increased psychotic symptoms and agitation, and as the staff recognized he was in no state to sleep by himself in his apartment, he was allowed to sleep on a mattress on the floor in the day room, despite their official standpoint concerning normalization and patients living in their own flats. After a few days, the client was able to return to his apartment in a nearby block of flats.

If a common approach was not maintained over time, and if it was not a temporary measure as in the case above, it was likely that the agreement process would start all over again if a new incident occurred similar to the one that had created the initial need for a common approach.

There were several reasons as to why a common approach would not be maintained: the action did not have the expected effect, the client still tried to hurt himself, or the staff had not yet reached an acceptable compromise. Consequently, some staff members did not feel any obligation to abide by the common approach that had been decided on. In one example, the staff had decided that a particular client had to be more involved in his shopping as training for handling his own money. The client was therefore obliged to accompany the staff to the supermarket when food was bought for him. Several members of the staff, however, went to 
the supermarket without the client because they thought it seemed to trouble him, and so the common approach did not persist over time.

Even when the staff put the common approach into practice there could still be difficulties in maintaining it during every meeting with the client, despite the consensus on appropriate action. A common approach could be too rigid for the actual situation even when the staff members interpreted it on an individual basis. This also made it difficult to maintain an agreement over time. For example, it seemed very difficult to regulate how private a staff member should be in her interaction with a client she visited every day and got to know well, even if the staff members had decided not to tell the client anything about their personal lives. One client narrated about a new member of staff he had met:

No, she was that stiff character right from the beginning. Staff said, what, you have no business with my private life! You have no business with that! And, My name is N. N., when she was answering the phone. But it was not alright with me. Is it Bill?, she said. No, I said, my name is not Bill. My name is William, remember that. As long as you answer with your full name, I said, I will do the same. It took three weeks and then it was over.

\section{DISCUSSION}

\section{Methodological considerations}

Grounded theory, first described by Glaser \& Strauss (1967), has been developed over the years in two directions, one being more realist-oriented (Glaser 1978) and one being more constructivist-oriented (Strauss \& Corbin 1998). In the latter approach, the researcher needs to include a definition and formulation of the phenomenon when stating the aim of the study, and should allow previous knowledge about the phenomenon to influence the analysis. The 
social processes that create the need for a common approach among staff in long-term psychiatric care have not previously been studied. On the other hand, naming the phenomenon as central to the investigation opens the investigation up for inductive derivation (cf. Strauss \& Corbin 1998) and could easily lead the investigator in a specific direction. However, this study, apart from pre-naming the phenomenon and consequently "risking" focusing on specific data, was inspired by the method developed by Glaser \& Strauss (1967) and the version later developed by Glaser (1978). When using grounded theory it is advisable to use multiple methods and sources for information in order to gain a deeper understanding. Thus, observations, interviews, focus group interviews, and memos were used simultaneously as means of data collection. Furthermore, since data from various milieus can be preferable, the data collected within the two units was supplemented by the inclusion in the study of four people outside the units, all of whom had lived experience as patients of being confronted with the common staff approach in their previous experience of psychiatric care.

Bunch (1983) states that since many people feel uncomfortable when they are being observed, the participants' acceptance of the observer is critical. Furthermore, the success of this study depended on people's willingness to share their personal experiences. It is therefore important to reflect on how to maintain the role of observer (cf. Rodgers \& Cowles 1993). In this case, the observer $(\mathrm{PE})$ had his own experience as a member of staff in similar situations to refer to. Although the use of two observers would have strengthened the rigor and authenticity, since aside from interviews, observations and field notes were the primary data, this was not possible under the circumstances. Instead memos were constantly written and, together with observation and interviews, monitored and discussed among all authors. The audit trail also proved to be a helpful source when validating data and securing internal rigor (cf. Rodgers \& Cowles 1993). 
Strauss \& Corbin (1998) raise several questions about how a study is grounded. They specifically underline the significance of each category. In this study, it was difficult to achieve categories which did not overlap one another. Sometimes, data seemed to fit in more than one category, necessitating further analysis. Though this only applied to a small proportion of the data collected, it still shows how easy it is to make the methodological error of forcing data into a specific category. This study should be seen as only the first step in uncovering the social processes which create the need among staff to formulate a common approach and to act towards individual clients in accordance with this approach.

Further research will be needed to work out the different parts of the theory. For example, another study has been performed with the aim of understanding the process of negotiation among staff when deciding on a common approach.

The main finding in this study was the importance, to staff, of maintaining or restoring order. This, then, also constituted the core category, "the preservation or restoration of order", which was interpreted and discussed within the framework of social order. Social order can be seen as a cultural phenomenon, which can change depending on contexts and cultures. Bauman (1995) believes that order in general can be seen as a regular and stable environment. Foucault (1983) has shown that social order in institutions implies that events and persons are put into a hierarchical system, which can be monitored and controlled. In long-term psychiatric care, this social order seems to be defined by the staff, and it regulates their actions and those of their patients with the aim of maintaining a stable care environment. Belief suspensions held by staff is then exposed in their thoughts and actions, and their attitudes towards the patient. However, the exposition of such beliefs was not the goal of this study; they must be studied separately. 
According to Bauman (1995, 1997), every order has its corresponding disorder. When something disturbs the order, we react to it and reflexively try to "return the vase to its rightful place". Here, the "vase" can be seen as a metaphor for social order; if moved from its original position then it must be replaced in it. In a way, it can be said that staff members react to a deviation by trying to modify a patient's behavior (cf. Skinner 1953) when the patient acts in a socially unacceptable manner. This strategy has its historical roots in the ideas of the 18th century, when the French physician Philippe Pinel liberated the insane from their chains (Foucault 1983), and those of the 19th century, about human nature and social order (Cohen 1985). For example, if a patient enters a prohibited area it might create a feeling of insecurity among staff if they cannot withdraw, since one essential part of care, which is seen as benefiting the patient, is control, which reinforces the staff's possibilities of restricting the patient's movements (Foucault 1983). Good care, i.e., collective care, with its dehumanizing routines and its suppression of the individual's autonomy, is a social system that is invisible to its actors (cf. Mumford 1973). However, when this strategy is used there is a risk that the caring process will become mechanical and that it will consequently have no effect on the psychiatric power structure (cf. Benjamin 1999).

Although it has been reported that a stable environment is good for psychiatric patients (National Board of Health and Welfare 1997a) it must be asked whether care staff confuse their own needs with those of the patients. This study has shown that nursing care is influenced by order and security as the staff, not the clients, perceive them. Even if the client is institutionalized partly because of his difficulties in coping with social norms, he is expected to adapt to the institution's norms, which may be much more restrictive than in society; for example, outside the institution, it would be the patient's choice as to whether to wear his outdoor clothes indoors, and he would not be told which hairstyles are acceptable or 
when/when not to drink coffee. Dolev (1976) reported three decades ago that when patients broke the social order it resulted in moral indignation on the part of the staff. Hellzén (2000) argues that there is a clear tendency in the uncompromising way that staff time care activities in situations when they feel the patient is demanding (e.g. patient seeking staff attention in a unwanted way). Patients who behave very provocatively towards staff make them aware of feelings they are trying to protect themselves from. This could also be seen in the present study.

The choice of action decided upon by common policy on how to deal with a client can be repressive. This ranges from suppressing initiatives that come from a client, to paternalism and subtle punishment. In this study, when staff agreed upon a way to act, their actions demonstrated that they had the power not only to define a correct lifestyle, but also to enter the client's personal zone, for example by deciding what was a suitable hairstyle. In such a case, the power held by the staff becomes more visible in the maintenance of structure and fixed routines. The staff deliberately treated the client as a child, acting with the (justifiable) authority of an adult, largely with the motivation to prevent harm and protect both themselves and the client from getting hurt. Foucault (1983) believes that power only exists when it is exercised. Therefore, power is difficult to perceive if you are not its target. However, when discussing power it is important to remember that all forms of compulsion, even those judged by society as legitimate, are seen as force by the person who is their victim (Bauman 2002). In a study by Mallander (1999), staff in group dwellings for mentally disabled people had several ways of controlling the residents in the name of obtaining normalization. One study about nurses' judgments of self-neglect among patients pointed out that the opinion held by different groups of nurses is a product of social judgment (Lauder et al. 2001) acquired in the subculture that the individual nurses have been exposed to. 
If staff perceive a situation as dangerous for a client it seems that they usually consider it in terms of physical injury, such as when the patient tries to hurt himself or neglects his meals; however when their own security is threatened they consider this in both physical and social terms. For example, in the present study, when the staff felt that a client was creating conflict among themselves they tried to handle the situation by assuming a common approach.

However, this study shows that it is usually difficult for staff to maintain a common approach over time. In those cases where the situation cannot be handled satisfactorily there will be no successful experience to fall back on when similar situations occur in the future. When staff are criticized by a patient it can be seen as an "inverted position of power", i.e., a shift of power from staff to the patient (cf. Hellzén et al. 1999). This is a probable explanation for the view, expressed by several members of staff, that the patients had all the privileges and the right to complain and that they, the nurses themselves, had no rights - "the order" maintained by the staff was turned upside down.

The negotiation among members of staff about how to act could be interpreted as an ongoing process in which only the reasons for negotiating are changed. It is possible to see this as helping individual staff members to "constantly check" whether their own opinions are in line with the rest of the ward. It is also possible that staff do not notice when they choose to come to a common approach on how to deal with a patient if their experiences of dealing with similar situations are "rich" and "successful". If their experiences are limited and/or negative it takes more effort for them to negotiate a suitable way of handling the situation.

In this study, it became obvious that it was difficult for the clients to reflect on the common approach among the staff and on why the staff had decided on certain forms of action. It is 
possible that when the staff agreed on how to act in a certain situation, the clients had little or no insight into this process; by contrast, if the staff disagreed with each other, the patients knew about it. According to Nyström (1999), people with long-term mental illness often have few social contacts and probably a narrower frame of reference for how to behave towards other people. Therefore, the way the staff behave towards the client can become "the natural way" if the patient has little outside experience to compare it with.

We argue this study has given a clearer picture on how common approach is used by staff in psychiatric long-term care, focusing on how they handle situations when under pressure from the client. The theory presented should be seen as the first step in uncovering the different aspects of common staff approach. Further, we argue that in order to improve care and strengthen the patient's involvement in the care situation, nurses and other staff need to increase their own awareness of their attitudes when their behavior towards the client is governed by a common approach. They also need to involve the client in decision making to a greater extent. Further studies are needed regarding the meaning of receiving and giving care using common approach among staff. 


\section{REFERENCES}

Bauman, Z. (1995). Life in Fragments. Essays in Postmodern Morality. Manchester, UK: Polity Press.

Bauman, Z. (1997). Postmodernity and its Discontents. Manchester, UK: Polity Press.

Bauman, Z. (2002). Society under Siege. Manchester, UK: Polity Press.

Benjamin, W. (1999). The work of art in the age of mechanical reproduction (German original 1936). In W. Benjamin, Illuminations. New York, NY: Pimilico.

Bunch, E. H. (1983). Everyday reality of the psychiatric nurse - a study of communication patterns between the schizophrenic and the psychiatric nurse. Dissertation, Oslo Norway: Gyldendal norsk forlag.

Cohen, S. (1985). Visions of Social Control. Manchester, UK: Polity.

Crabtree, S. A. (2003). Asylum blues: staff attitudes towards psychiatric nursing in Sarawak, East Malaysia. Journal of Psychiatric \& Mental Health Nursing, 6, 713-722.

Dolev, A. (1976). A medical model versus a normative approach: the place of values in community psychiatry. Mental Health Society, 3, 92-101.

Foucault, M. (1983). Madness and Civilization (French original 1961). London, UK: Routledge.

Foucault, M. (1987). Discipline and Punish (French original 1975). Harmondsworth, Middlesex, UK: Penguin Books.

Glaser, B. (1978). Theoretical Sensitivity. Advances in Methodology of Grounded Theory. Mill Valley, CA: Sociology Press.

Glaser, B., Strauss, A. (1967). The Discovery of Grounded Theory. Strategies for Qualitative Research. New York, NY: Aldine.

Goffman E 1(971) The Presentation of Self in Everyday Life. Penguin. 
Goffman, E. (1991). Asylum: Essays on the Social Situation of Mental Patients and Other Inmates. London, UK: Penguin Books.

Hellzén, O. (2000). The Meaning of Being a Carer for People with Mental Illness and Provoking Actions: Carers' Exposure in Problematic Care Situations. Umeå University, Umeå, Sweden: Medical Dissertations.

Hellzén, O., Norberg, A., Sandman, P. O. (1995). Schizophrenic patients' image of their carers and the carers' image of their patients: an interview study. Journal of Psychiatric and Mental Health Nursing, 2, 279-285.

Hellzén, O., Asplund, K., Sandman, P. O., Norberg, A. (1999). The unwillingness to be violated: carers' experiences of caring for a person acting in a disturbing manner. An interview study. Journal of Clinical Nursing, 8, 653-662.

Hornby, A. S. (1974). Oxford Advanced Dictionary of Current English. London: Oxford University press, Third edition.

Kvale, S. (1996). Interviews - an Introduction to Qualitative Research Interviewing. London, UK: Sage.

Lauder, W., Scott, A., Whytt, A. (2001). Nurses' judgements of self-neglect: a factorial survey. International Journal of Nursing Studies, 38, 601-608.

Lutzén, K. (1998). Subtle coercion in psychiatric practice. Journal of Psychiatric \& Mental Health Nursing, 2, 101-107.

Lutzén, K., Schreiber, R. (1998). Moral survival in a nontherapeutic environment. Issues of Mental Health Nursing, 4, 303-315.

Mallander, O. (1999). De hjälper oss till rätta. (They Help us Out-Normalization Work, Self-Determination and People with Learning Disabilities) [In Swedish, with English summary]. Lund University, Lund, Sweden: Institution for Social Work. Mumford, L. (1973). Utopia, the city and the machine. In F. F. Manuel (Ed.) Utopia and 
Utopian Thoughts. England: Souvenir Press.

National Board of Health and Welfare (1997a). Vårdmiljöns betydelse för innehåll och kvalitet $i$ den psykiatriska vården (Importance of the Ward Milieu in Relation to Care Content and Quality in Psychiatric Care) [In Swedish]. Stockholm, Sweden: National Board of Health and Welfare, volume 10.

National Board of Health and Welfare (1997b). Ideologier, kulturer och synsätt inom psykiatrin. (Ideologies, Cultures and Perspectives in Psychiatry) [In Swedish]. Stockholm, Sweden: National Board of Health and Welfare, volume 16.

National Board of Health and Welfare (1999). Välfärd och Valfrihet. Slutrapport från utvärderingen av 1995 års psykiatrireform. (Welfare and Freedom of Choice. Conclusive report from 1995 years psychiatry reform). [In Swedish]. Stockholm, Sweden: National Board of Health and Welfare.

Nyström, M. (1999). Allvarligt psykiskt störda människors vardagliga tillvaro. (The Daily Life of Severely Mentally Ill People) [In Swedish, with English summary]. Doctoral thesis, Gothenburg, Sweden: Acta Universitatis Gothoburgensis.

Patton, M. Q. (1990). Qualitative Evaluations and Research Methods. USA: Sage.

Pejlert, A., Asplund, K., Norberg, A. (1995). Stories about living in a hospital ward narrated by schizophrenic patients. Journal of Psychiatric and Mental Health Nursing, 2, 269-277.

Pejlert, A., Asplund, K., Gilje, F., Norberg, A. (1998). The meaning of caring for patients on a long-term psychiatric ward as narrated by formal care providers. Journal of Psychiatric and Mental Health Nursing, 5, 255-264.

Polit, D. F., Hungler, B. P. (1999). Nursing Research, Principles and Methods (6th ed.). Philadelphia, PA: J. B. Lippincott Company.

Rodgers, B. L., Cowles, K. V. (1993). The qualitative research audit trail: a complex 
collection of documentation. Research in Nursing \& Health, 16, 219-226.

Sarvimäki, A., Sandelin Benkö, S. (1998). Culture and climate 1: investigating aspects of organizational and care culture by use of proverbs. Vård i Norden (Nursing Science and Research in the Nordic Countries), 2, 26-30, 36.

Shepherd, G., Muijen, M., Dean, R., Cooney, M. (1995). Inside Residential Care. Realities of Hospitals versus Community Settings. London, UK: The Sainsbury Centre for Mental Health.

Sjöström, B. (1992). Kliniken tar över dårskapen - Om den moderna psykiatrins framväxt. (The Insanity is Taken Over by the Clinic) [In Swedish, with English summary]. Dissertation, Gothenburg, Sweden: Daidalos.

Skinner, B. F. (1953). Science and Human Behaviour. New York, NY: MacMillan.

Skovdahl, K., Kihlgren, A. L., Kihlgren, M. (2003). Different attitudes when handling aggressive behaviour in dementia - narratives from two caregiver groups. Aging \& Mental Health, 7, 227-286.

Starrin, B., Dahlgren, L., Larsson, G., Styrborn, S. (1997). Along the Path of DiscoveryQualitative Methods and Grounded Theory. Lund, Sweden: Studentlitteratur.

Stenbak, E., Barfod, A., Andersen, C. (2000). Social Psychiatry in the Nordic Countries. Copenhagen, Denmark: Social Development Centre SUS.

Strauss, A., Corbin, J. (1998). Basic of Qualitative Research - Techniques and Procedures for Developing Grounded Theory (2nd ed.). Sage.

Stuart, G. W., Sundeen, S. J. (1995). Principles and Practices of Psychiatric Nursing (5th ed.). St. Louis, MO: C. V. Mosby.

Zimmerman, D. P. (1996). A comparison of commonly used treatment measures. In S. I. Pfeiffer (Ed.) Outcome Assessment in Residential Treatment (pp. 49-71). New York, NY: The Hawthorne Press, Bingham. 
Åström, T., Dufåker, M., Jacobsson, L. (1993). Discharge procedures for mentally ill people. Scandinavian Journal of Social Welfare, 2, 33-42. 